\title{
ENHANCEMENT OF GLIBENCLAMIDE DISSOLUTION RATE BY SOLID DISPERSION METHOD USING HPMC AND PVP
}

\section{ARIF BUDIMAN*, IYAN SOPYAN, DENIA SEPTY RIYANDI}

Department of Pharmaceutics and Pharmaceutical Technology, Faculty of Pharmacy, Universitas Padjadjaran

Email: arif.budiman@unpad.ac.id

Received: 15 May 2019, Revised and Accepted: 06 Jun 2019

\section{ABSTRACT}

Objective: The aim of this study was to investigate the effects of changing in the proportions of the solid dispersion formula on the dissolution rate of glibenclamide.

Methods: Solid dispersions were prepared by solvent evaporation method by using methanol as solvent, hydroxypropyl methylcellulose (HPMC) and polyvinyl pyrrolidone (PVP) as polymers. The prepared product was evaluated by the saturated solubility test and the dissolution rate test. The prepared product was characterized by Fourier transform infrared spectroscopy (FT-IR), differential scanning calorimetry (DSC), and powder X-ray diffraction (PXRD) and Scanning Electron Microscopy (SEM).

Results: The result showed solid dispersion with a ratio of glibenclamide: PVP: HPMC (1: 3: 6) has the highest increase in solubility (20 fold) compared to pure glibenclamide. This formula also showed an improvement in dissolution rate from $19.9 \pm 1.19 \%$ (pure glibenclamide) to $99 \pm 1.60 \%$ in 60 min. Characterization of FT-IR showed that no chemical reaction occurred in solid dispersion of glibenclamide. The results of Xray diffraction analysis showed an amorphous form in all solid dispersion formulas. The results of DSC analysis showed that endothermic peak melting point of solid dispersion occurred, and the morphology of solid dispersion was more irregular than pure glibenclamide based on SEM characterization

Conclusion: The solid dispersion of glibenclamide using PVP: HPMC as carriers can increase the solubility and dissolution rate compared to pure glibenclamide.

Keywords: Dissolution Rate, Glibenclamide, Solid Dispersion, HPMC, PVP

(C) 2019 The Authors. Published by Innovare Academic Sciences Pvt Ltd. This is an open-access article under the CC BY license (http://creativecommons.org/licenses/by/4.0/) DOI: http://dx.doi.org/10.22159/ijap.2019v11i5.34137

\section{INTRODUCTION}

One of the most widely used drug routes of administration is the oral route. The oral route has several advantages, including ease of administration, patient compliance, cost-effective and flexible dosage settings. However, the challenge in developing drugs with oral routes is their bioavailability, because many factors can affect bioavailability include permeability, solubility, dissolution rate and first pass metabolism [1].

Solubility is an important parameter of the absorption process of a drug The poor water solubility of drug can exhibit poor bio-availability in the drug absorption [2]. Based on the BCS system, there are around $40 \%$ of drug drugs that have been marketed that have low solubility, which can cause poor dissolved in the GI fluids. One of a drug that belongs to class II, according to BCS is glibenclamide (has high permeability, but low solubility). The solubility of glibenclamide in water is equal to $4 \mathrm{mg} / \mathrm{l}$ [3]. The low solubility of glibenclamide in water causes a low ability of glibenclamide to reach the systemic circulation and results in poor bioavailability of the drug. The bioavailability of glibenclamide is known at $40-45 \%$ after oral dosing [4]. Therefore, increasing the solubility and dissolution of glibenclamide is important to improve the efficiency of administration of glibenclamide in oral preparations [5].

Several techniques can be used to increase the solubility and dissolution of the drug such as complexation, the salts formation, particle size reduction, cocrystallization and solid dispersion [1]. Solid dispersion applications have widely been used to improve the solubility and oral bioavailability of the drug [6]. Kaur and Kumar reported that the solid dispersion technique was able to increase glibenclamide solubility from $78.85 \pm 0.001 \mu \mathrm{g} / \mathrm{ml}$ to $260.00 \pm 0.006$ $\mu \mathrm{g} / \mathrm{ml}$ and increased the dissolution rate from $22.41 \%$ to $93.98 \%$ within $60 \mathrm{~min}$. Some advantages of solid dispersion techniques are simple, do not require a lot of equipment and can increase dissolution rates [7]
In this study, glibenclamide solid dispersion was prepared using PVP K30 and HPMC as a polymer by solvent evaporation method in different ratios. Sangeetha et al. reported that using HPMC as a solid dispersion polymer can increase the solubility of drug 10 fold compared with pure drugs, while for PVP K30 can increase 2.5 fold. Dissolution rate at 5 min using HPMC as polymer was $98 \%$, PVP $66.3 \%$ and pure drug 57\% [8]. PVP and HPMC also can inhibit the crystallization of the drug from an amorphous state during the solvent removal process [9].

\section{MATERIALS AND METHODS}

\section{Materials}

Glibenclamide (PT. Indofarma Tbk), HPMC, PVP (Nanhang Industrial Co LTD), methanol, potassium hydrogen phosphate, potassium dihydrogen phosphate, Sodium Hydroxide (all reagents are analytical grade).

\section{Methods}

\section{Preparation of solid dispersion}

Solid dispersion of glibenclamide was prepared by mixing Glibenclamide and carriers according to the formula in table 1. Glibenclamide, HPMC and PVP K30 were dissolved in methanol and mixed using a magnetic stirrer until homogeneous solution. The mixture solution was evaporated at a temperature of $50-60{ }^{\circ} \mathrm{C}$ for 24 $\mathrm{h}$ to obtain a dried sample [10].

\section{Determination of drug content}

Solid dispersion of glibenclamide equivalent to $50 \mathrm{mg}$ of glibenclamide was weighed and dissolved in methanol. The solution was filtered through a $0.45 \mu \mathrm{m}$ membrane filter, and the amount of the drug dissolved was analyzed spectrophotometrically at $300 \mathrm{~nm}$ [11]. 
Table 1: Binary and ternary solid dispersion formula of glibenclamide

\begin{tabular}{|c|c|c|c|}
\hline Formula & Glibenclamide (\%) & PVP (\%) & HPMC (\%) \\
\hline F1 & 10 & 90 & \\
\hline $\mathrm{F} 2$ & 20 & 80 & \\
\hline F3 & 30 & 70 & \\
\hline $\mathrm{F} 4$ & 40 & 60 & \\
\hline F5 & 50 & 50 & \\
\hline F6 & 60 & 40 & \\
\hline F7 & 70 & 30 & \\
\hline F8 & 80 & 20 & \\
\hline F9 & 90 & 10 & \\
\hline F10 & 10 & & 90 \\
\hline F11 & 20 & & 80 \\
\hline F12 & 30 & & 70 \\
\hline F13 & 40 & & 60 \\
\hline F14 & 50 & & 50 \\
\hline F15 & 60 & & 40 \\
\hline F16 & 70 & & 30 \\
\hline F17 & 80 & & 20 \\
\hline F18 & 90 & & 10 \\
\hline F19 & 10 & 30 & 60 \\
\hline $\mathrm{F} 20$ & 20 & 20 & 60 \\
\hline $\mathrm{F} 21$ & 30 & 35 & 35 \\
\hline
\end{tabular}

\section{Evaluation}

\section{Solubility test}

Solid dispersion of glibenclamide equivalent to $10 \mathrm{mg}$ of glibenclamide was weighed and placed into Erlenmeyer flask that contained water. The samples were agitated using a mechanical agitator for $24 \mathrm{~h}$ and 48 $h$ at room temperature. The saturated solutions were filtered through a $0.45 \mu \mathrm{m}$ membrane filter, and the amount of the drug dissolved was analyzed spectrophotometrically at $300 \mathrm{~nm}[12,13]$.

\section{Dissolution test}

Solid dispersions equivalent to $20 \mathrm{mg}$ of glibenclamide were put into $900 \mathrm{ml}$ of $\mathrm{pH} 8$ phosphate buffer solution with a paddle speed of 75 rpm. $5 \mathrm{ml}$ of samples were taken at intervals of 5, 10, 15, 20, 30, 45, 60 min. Each sample taken was replaced with $5 \mathrm{ml}$ of dissolution medium. The dissolution samples were filtered through a syringe filter of 0.45 $\mu \mathrm{m}$ pore size and analyzed spectrophotometrically at $300 \mathrm{~nm}[12,13]$.

\section{Characterization of solid dispersion}

\section{Powder X-ray diffraction (PXRD)}

Crystal structures were analyzed by PXRD (Phillips PW1835® diffractometer) with the following conditions: target/filter (monochromator) $\mathrm{Cu}$, voltage $40 \mathrm{kV}$ and a tube current $30 \mathrm{~mA}$. Data was collected by scanning mode $0.2^{\circ}-0.5^{\circ}$ per minute with scanning distances of $2 \theta=5^{\circ}-60^{\circ}$ [14].

\section{Differential scanning calorimetry (DSC)}

Thermal analysis of solid dispersion was conducted using DSC. A thermograph was recorded under a nitrogen gas flow at a flow rate of $50 \mathrm{ml} / \mathrm{min}$. Samples were evaluated from 30 to $300{ }^{\circ} \mathrm{C}$ with a heating rate of $10^{\circ} \mathrm{C} / \mathrm{min}[15]$.

\section{Fourier transform infrared (FTIR)}

The infrared spectrum of the samples was recorded using an infrared spectrophotometer using the $\mathrm{KBr}$ pellet. The infrared spectrum was recorded at $4000-400 \mathrm{~cm}^{-1}$ wavenumbers [16].

\section{Scanning electron microscope (SEM)}

Sample powders were placed on the sample holder aluminum (each formula and pure glibenclamide) coated with gold. The sample was analyzed by SEM (JSM6510, JEOL) with voltage acceleration obtained at $15 \mathrm{kV}[15,17]$.

\section{Data analysis}

Analysis of solubility and dissolution test data were presented as a mean of samples \pm standard deviation (SD) and were analyzed using the one-way analysis of variance (ANOVA) at the level of $(\mathrm{P}<0.05)$ [18].

\section{RESULTS AND DISCUSSION}

\section{Preparation of solid dispersion}

Solid dispersion was prepared using the solvent evaporation method. In this method, the drug and polymer were dissolved in an organic solvent and evaporated to obtain dried sample [19]. Through this process, the drug will be dispersed molecularly in the polymer matrix [20]. PVP is a hydrophilic polymer commonly used as carriers for solid dispersions to increase solubility and dissolution of poorly water-soluble drug $[11,21]$. HPMC is a water-soluble polymer that can be used as carriers for solid dispersion. Many drugs have been successfully prepared for solid dispersion using HPMC as a carrier. HPMC in particular cellulose can adsorb hydrophobic drug surfaces by the presence of methoxyl or hydroxypropyl groups $[20,22]$.

\section{Content determination}

Table 2: Result of content determination of glibenclamide solid dispersion

\begin{tabular}{llll}
\hline No & Formula & Average content & SD \\
\hline 1 & F1 & 94.32 & $0.019 \%$ \\
2 & F5 & 98.42 & $0.008 \%$ \\
3 & F9 & 96.70 & $0.013 \%$ \\
4 & F10 & 93.02 & $0.017 \%$ \\
5 & F14 & 96.31 & $0.010 \%$ \\
6 & F18 & 94.44 & $0.020 \%$ \\
7 & F19 & 90.00 & $0.020 \%$ \\
8 & F20 & 95.48 & $0.017 \%$ \\
9 & F21 & 95.75 & $0.020 \%$ \\
\hline
\end{tabular}




\section{Solubility test}

The result of the solubility study of glibenclamide solid dispersion can be seen in fig. 1.

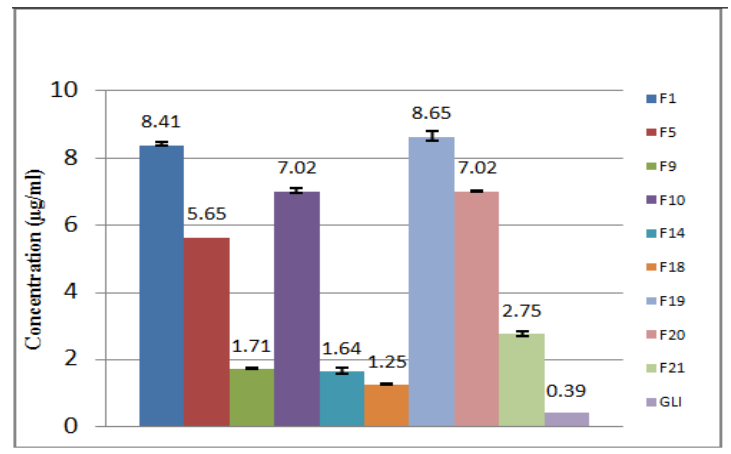

(a)

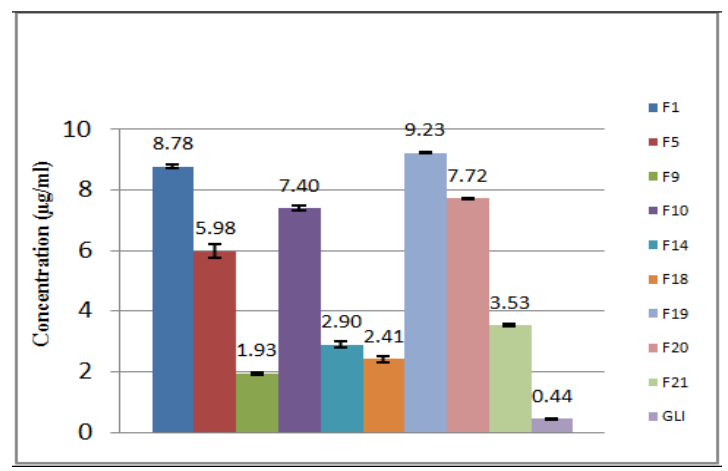

(b)

Fig. 1: The result of solubility study of glibenclamide solid dispersion (a) after $24 \mathrm{~h}$ and (b) after $48 \mathrm{~h}$ (All the values were calculated as mean \pm standard deviation) $(n=3)$
The result showed that all solid dispersion formulas increase the solubility of glibenclamide compared with pure glibenclamide. The highest increase in solubility was in Formula 19 (GLB: HPMC: PVP (1:6:3) with a saturated solubility of $9.23 \pm 0.012 \mu \mathrm{g} / \mathrm{ml}$ compared to the solubility of pure glibenclamide of $0.44 \pm 0.006 \mu \mathrm{g} / \mathrm{ml}$. The increase in solubility of this solid dispersion can be caused by the molecular dispersion of the drug in the hydrophilic polymer so that the wettability of the drug will increase. The presence of HPMC and PVP can form the intermolecular hydrogen bonding with glibenclamide [11]. The result of the solubility study was analyzed statistically and showed that the solubility of all solid dispersion formula were significant differences $(\rho<0.05)$ compared with pure glibenclamide.

\section{Dissolution test}

The dissolution test results of pure glibenclamide were $19.9 \pm 1.19 \%$ in $60 \mathrm{~min}$. The highest dissolution result was formula $19(99 \pm 1.60 \%)$. Based on these results, it is known that there was an increase in the dissolution rate of glibenclamide solid dispersion compared to pure drugs. The mechanism of solid dispersion for the improvement of dissolution rate of the drug are particle size reduction of drug, formation of an amorphous state and improved wettability. Based on the results, HPMC and PVP can form an amorphous state with intermolecular hydrogen bond, inhibit crystallization of drug and enhance wettability $[22,8]$.

In a ternary solid dispersion system with a mixture of PVP and HPMC polymers there is a combination of a mechanism for increasing dissolution rates of active substances. PVP has properties that can increase dissolution of the drug, whereas HPMC will produce high dispersion with high porosity having a synergistic effect that will increase dissolution rates compared with the use of single polymers. Ohyagi et al. reported that a synergistic effect was obtained from a combination of HPMC and eudragit which can increase the griseofulvin dissolution rate [15] The result of the dissolution study was analyzed statistically and showed that the dissolution of the solid dispersion formula were significant differences $(\rho<0.05)$ compared with pure glibenclamide.

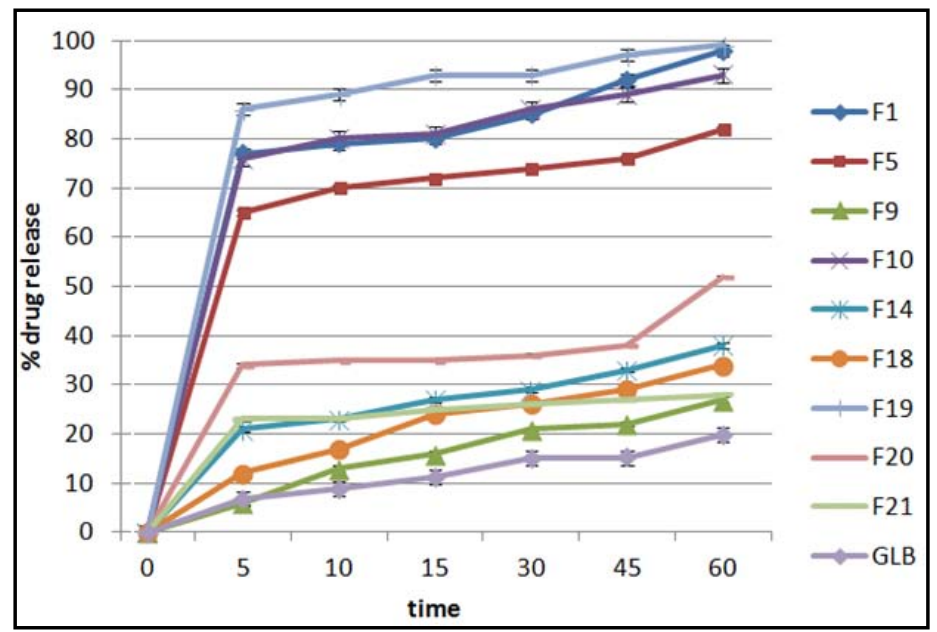

Fig. 2: The result of the dissolution study of glibenclamide solid dispersion (All the values were calculated as mean \pm standard deviation) (n=3)

\section{Powder X-Ray diffractometer (PXRD)}

The pure glibenclamide showed diffractogram peak with the highest intensity at an angle of $2 \theta=10.7^{\circ}, 12.3^{\circ}, 19.5^{\circ}, 19.8^{\circ}, 20.9^{\circ}, 22.1^{\circ}$ which indicates that glibenclamide is in the crystalline state. Whereas for F1 solid dispersions containing $10 \%$ glibenclamide and $90 \%$ PVP, there is halo pattern diffractogram but still found the peak at $2 \theta=10.5^{\circ}, 11.3^{\circ}, 19.7^{\circ}, 20.8^{\circ}, 21.7^{\circ}$ and $22.2^{\circ}$, but the intensity was relatively lower compared to the intensity of the peak on a pure glibenclamide diffractogram. In the F10 solid dispersion containing $10 \%$ glibenclamide and 90\% HPMC, there was also a halo pattern diffractogram with less peak observed, with relatively lower intensity compared to pure glibenclamide, the highest intensity obtained at an angle of $2 \theta=19.6^{\circ}, 20.1^{\circ}, 31.7^{\circ}$ and $45.4^{\circ}$. While the ternary solid dispersion formula does not appear diffractogram peak characteristic of glibenclamide. It is indicated that the molecular state of glibenclamide in ternary solid dispersion was in an amorphous state [23]. Any changes in diffractogram peak 
characteristic of glibenclamide, when formulated into a solid dispersion, indicated that the molecular state of the drug already changed from crystalline state to amorphous state. Changes in crystallinity of glibenclamide could be one of the mechanisms responsible for improving the solubility and dissolution of glibenclamide [11].

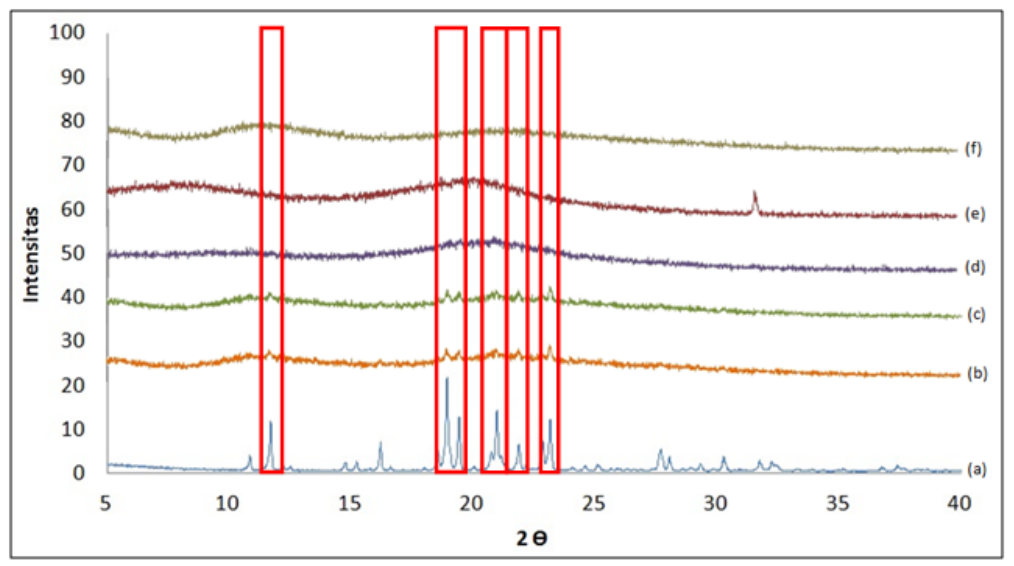

Fig. 3: PXRD result of glibenclamide (a), F1 (b), F10 (c), F19 (d), HPMC (e), PVP (f)

\section{Differential scanning calorimetry (DSC)}

In the thermogram of DSC, the endothermic peak of pure glibenclamide was on $176.6^{\circ} \mathrm{C}$, indicating its crystalline nature. The thermal behavior of the PVP and HPMC are amorphous substances, with a large endothermal effect in the $60-100{ }^{\circ} \mathrm{C}$ range due to polymer dehydration [11]. No endothermic peaks corresponding to glibenclamide were observed in solid dispersions prepared by the solvent evaporation method. This is assumed that HPMC and PVP in solid dispersion can inhibit the crystallization of glibenclamide through hydrogen bonding between polymers with glibenclamide [22].

According to gracin et al., the solubility of a compound or material has a correlation with its thermodynamic properties, the thermodynamic properties can be either the melting or enthalpy of the substance [24]. In relation to solubility, enthalpy shows changes in the relative energy needed to break the bonds between solute molecules so that the smaller enthalpy energy needed to break down the solute bonds becomes lower and solubility becomes higher [25].

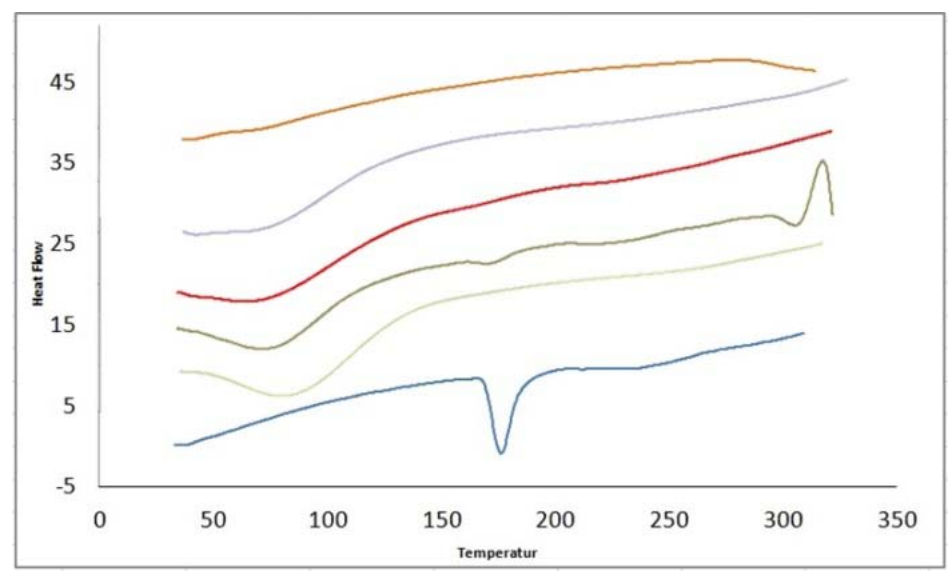

Fig. 4: DSC thermogram of glibenclamide (blue line), PVP (gray line), HPMC (green line), F1 (red line), F10 (purple line) and F19 (brown line)

\section{Fourier transform infrared (FTIR)}

The FTIR spectra of pure glibenclamide showed a peak at wave number $3413 \mathrm{~cm}^{-1}$ ((NH stretch), 3116-1 (OH stretch), 2390-1 (CH stretch), $1712^{-1}\left(\mathrm{C}=0\right.$ stretch) $1612^{1}\left(\mathrm{C}=\mathrm{C}\right.$ stretch and $1350^{-1}$ $(\mathrm{CH})$ amines according to the characteristics of the glibenclamide structure. The PVP polymer shows a peak at wave number $1655^{-1}$ caused by the presence of carbonyl groups, 29551 due to $\mathrm{CH}$ stretch and at $3450^{-1}(\mathrm{OH})$ which indicates the presence of moisture due to the hygroscopic nature of PVP. The HPMC FTIR spectra show that the wide peaks at wavenumber
$3470^{-1}$ show $\mathrm{OH}$ stretch, this is consistent with the research conducted [26].

Whereas for the solid dispersion of F1, there are still peaks at 3439-1 (OH stretch), 2961-1 (CH stretch), 1651-1 (CO stretch) and CN at wave number $1299^{-1}$. For solid dispersion F10, a cluster is still found. The $\mathrm{OH}$ function at wave number $3480^{-1}, \mathrm{CH}$ at $2975^{-1}, \mathrm{C}=\mathrm{C}$ at $1628^{-1}$ and $\mathrm{CN}$ at $1350^{1}$. For F19 solid dispersions, an $\mathrm{OH}$ functional group was found stretching at $3452^{-1}$, CH at $2972^{-1}, \mathrm{C}=\mathrm{C}$ at $1650^{-1}$ and amine (CN) in $1297^{1}$. This indicates that no chemical reaction occurred in the solid dispersion of glibenclamide. 


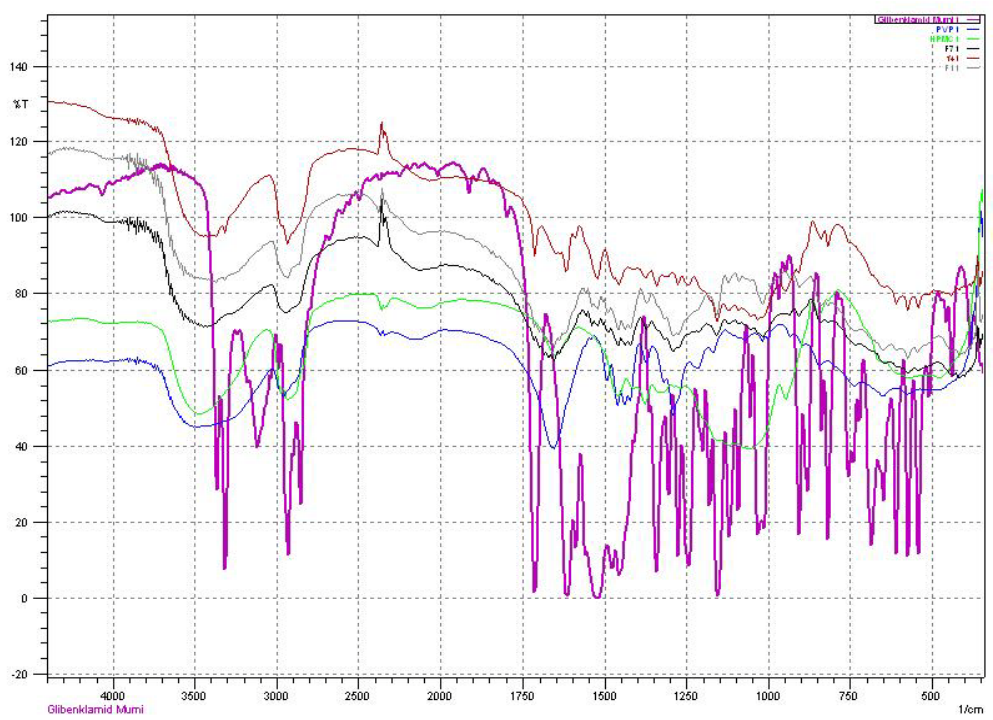

Fig. 5: FTIR spectrum of glibenclamide (purple line), PVP (blue line), HPMC (green line), F1 (black line), F10 (gray line) and F19 (brown line)

\section{Scanning electron microscopy (SEM)}

Morphology of pure glibenclamide, HPMC, PVP, and solid dispersion of glibenclamide can be seen in fig. 6. The morphology of solid dispersion did not show a characteristic of glibenclamide crystal. It

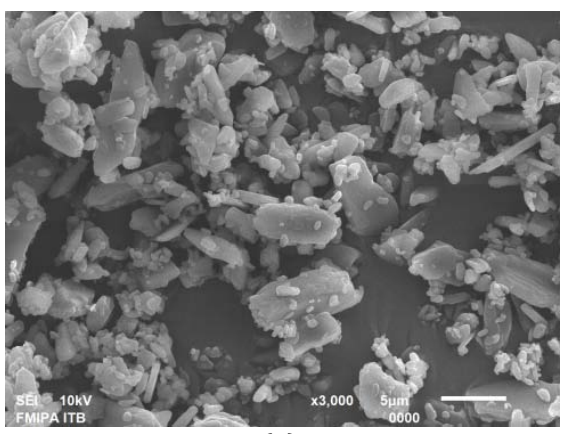

(a)

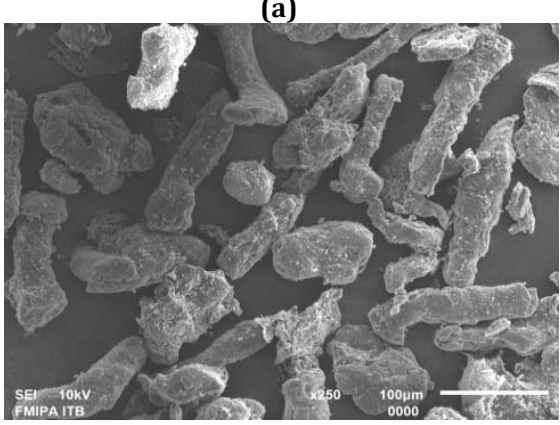

(c)

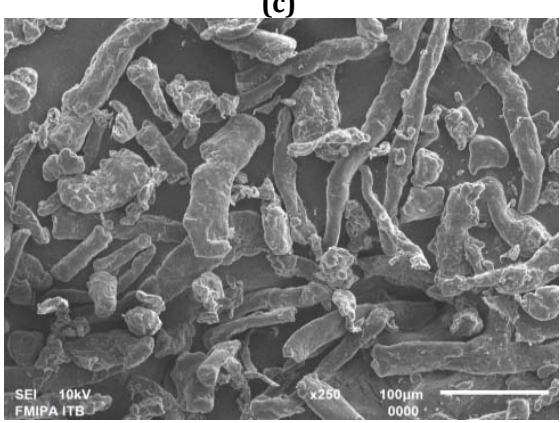

(e) is assumed that glibenclamide was dispersed in HPMC and PVP. The irregular shape of the solid dispersion is related to the wettability of a solid form, although the average solid dispersion particles have a larger size but irregular shapes can increase the wettability of the active substance so that the solubility increases $[17,27]$.
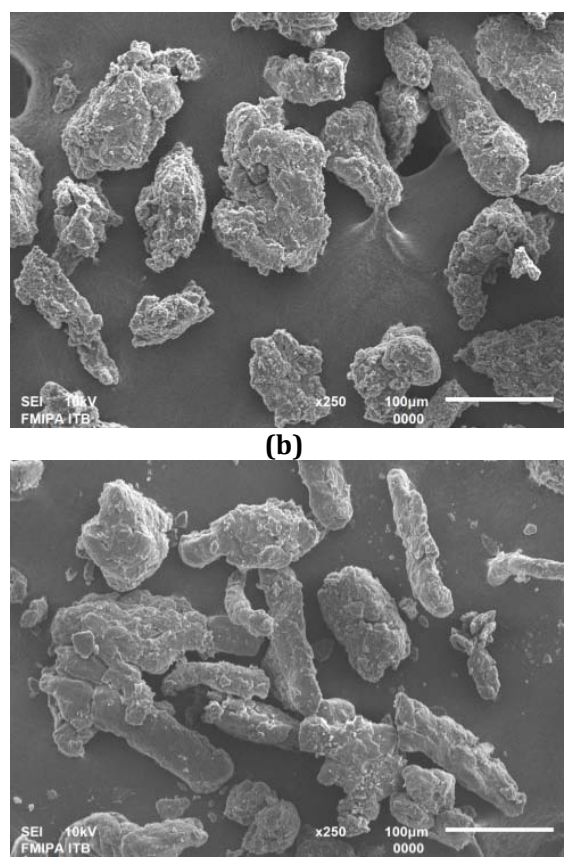

(d)

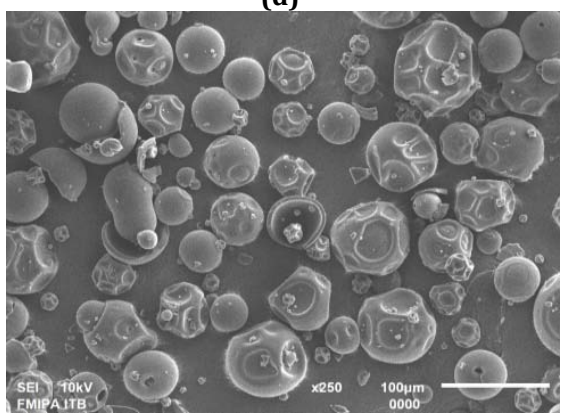

(f)

Fig. 6: SEM electromicrophotograph of (a) glibenclamide, (b) Solid dispersion of F1, (c) F10, (d) F19, (e)HPMC, (f) PVP 


\section{CONCLUSION}

The solid dispersion of glibenclamide using PVP: HPMC as carriers can increase the solubility and dissolution rate compared to pure glibenclamide. Solid dispersion with a ratio of glibenclamide: PVP: HPMC (1: 3: 6) has the highest increase in solubility (20 fold) compared to pure glibenclamide. This formula also showed an improvement in dissolution rate from 19.9 $\pm 1.19 \%$ (pure glibenclamide) to $99 \pm 1.60 \%$ in $60 \mathrm{~min}$. Characterization of FT-IR showed that no chemical reaction occurred in solid dispersions of glibenclamide. The results of X-ray diffraction analysis showed an amorphous form in all solid dispersion formulas. The results of DSC analysis showed that endothermic peak melting point of solid dispersion occurred, and the morphology of solid dispersion was more irregular than pure glibenclamide based on SEM characterization.

\section{ACKNOWLEDGMENT}

The authors thank to Universitas Padjadjaran for the financial support for this research in scheme Riset Fundamental Unpad 2018.

\section{CONFLICTS OF INTERESTS}

All authors have none to declare

\section{AUTHORS CONTRIBUTIONS}

All the authors contributed equally to this work

\section{REFERENCES}

1. Chaturvedi AK, Amita V. Solubility enhancement of poorly water-soluble drugs by solid dispersion. Int J Pharm Sci Rev Res 2012;3:26-34.

2. $\mathrm{Hu}$ J, Johnston KP, Williams RO. Nanoparticle engineering processes for enhancing the dissolution rates of poorly watersoluble drugs. Drug Dev Ind Pharm 2004;30:233-45.

3. Yalkowsky SH, Dannenfelse RM. Aquasol database of aqueous solubility. Arizona: College of Pharmacy, University of Arizona, Tucson; 1992. p. 189.

4. Kumar A, Bali V, Kumar M, Pathak K. Comparative evaluation of porous versus nonporous mucoadhesive films as buccal delivery system of glibenclamide. AAPS PharmSciTech 2013;14:1321-32.

5. Khadka P, Ro J, Kim H, Kim I, Kim JT, Kim H, et al. Pharmaceutical particle technologies: an approach to improve drug solubility, dissolution and bioavailability. Asian J Pharm Sci 2014;9:304-16.

6. Vojinovic T, Medarevic D, Vranic E, Potpara Z, Krstic M, Djuris J, et al. Development of ternary solid dispersions with hydrophilic polymer and surface adsorbent for improving the dissolution rate of carbamazepine. Saudi Pharm J 2018;26:725-32.

7. Craig DQ. The mechanism of drug release from solid dispersions in water-soluble polymers. Int $\mathrm{J}$ Pharm 2002;231:131-44.

8. Sangeetha E, Rao VU, Sudhakar M, Manisha S. Enhancement of solubility and bioavailability of hydrochlorothiazide using solid dispersion technique. Am J Adv Drug Delivery 2015;3:308-16.

9. Suzuki H, Sunada H. Influence of water-soluble polymers on the dissolution of nifedipine solid dispersions with combined carriers. Chem Pharm Bull 1998;46:482-7.
10. Singh D, Dua JS, Prasad DN. Formulation and evaluation of glibenclamide tablet using solid dispersion with various polymer. Asian J Pharm Res Dev 2018;6:81-6.

11. Sharma A, Jain CP. Preparation and characterization of solid dispersions of carvedilol with PVP K30. Res Pharm Sci 2010;5:49-56.

12. Bari A, Chella N, Sanka K, Shastri NR, Diwan PV. Improved antidiabetic activity of glibenclamide using oral self nano emulsifying powder. J Microencapsul 2015;32:54-60.

13. Dora CP, Singh SK, Kumar S, Datusalia AK, Deep A. Development and characterization of nanoparticles of glibenclamide by solvent displacement method. Acta Pol Pharm Drug Res 2010;67:283-90.

14. Budiman A, Megantara S, Raraswati P, Tazyinul QA. Solid dosage form development of glibenclamide with increasing the solubility and dissolution rate using cocrystallization. Int J Appl Pharm 2018;10:181-6.

15. Ohyagi N, Ueda K, Higashi K, Yamamoto K, Kawakami K, Moribe $\mathrm{K}$. Synergetic role of hypromellose and methacrylic acid copolymer in the dissolution improvement of amorphous solid dispersions. J Pharm Sci 2017;106:1042-50.

16. Vinesha V, Sevukarajan M, Rajalakshmi R, Chowdary GT, Haritha K. Enhancement of solubility of tadalafil by cocrystal approach. Int Res J Pharm 2016;4:218-23.

17. Fitriani L, Haqi A, Zaini E. Preparation and characterization of solid dispersion freeze-dried efavirenz-polyvinylpyrrolidone K-30. J Adv Pharm Technol Res 2016;7:105-9.

18. Budiman A, Khoerunnisa R, Tazyinul QA. Wound-healing test of piper betle leaf extract and aloe vera in gel preparation. Int J Appl Pharm 2018;10:86-91.

19. Tachibana T, Nakamura A. Method for preparing an aqueous colloidal dispersion of organic materials by using water-soluble polymers: dispersion of beta-carotene by polyvinylpyrrolidone. Colloid Polym Sci 1965;203:130-3.

20. Singh S, Baghel RS, Yadav L. A review on solid dispersion. Int J Pharm Life Sci 2011;2:1078-95.

21. Chiou W, Riegelman S. Pharmaceutical applications of solid dispersion systems. J Pharm Sci 1971;60:1281-302.

22. Douroumis D, Bouropoulos N, Fahr A. Physicochemical characterization of solid dispersions of three antiepileptic drugs prepared by solvent evaporation method. J Pharm Pharm 2007;59:645-53.

23. Mishra MK, Ray D, Barik BB. Microcapsules and transdermal patch: a comparative approach for improved delivery of an antidiabetic drug. AAPS PharmSciTech 2009;10:928-34.

24. Gracin S, Rasmuson AC. Solubility of phenylacetic acid, phydroxyphenyl acetic acid, p-aminophenylacetic acid, phydroxybenzoic acid, and ibuprofen in pure solvents. J Chem Eng 2002;47:1379-83.

25. Augustjins P, Brewster ME. Biotechnology: pharmaceutical aspect solvent systems and their selection in biopharmaceutics. 6th ed. New York: AAPS Press; 2007.

26. El Maghraby GM, Elsergany RN. Fast disintegrating tablets of nisoldipine for intra-oral administration. Pharm Dev Technol 2014;19:641-50.

27. Elbary AA, Salem HF, Maher ME. In vitro and in vivo evaluation of glibenclamide using solid surface dispersion (SSD) approach. Br J Pharm Toxic 2011;2:51-62. 